\title{
The Chromatin Regulator CHD8 Is a Context- Dependent Mediator of Cell Survival in Murine Hematopoietic Malignancies
}

\author{
Jennifer R. Shingleton, Michael T. Hemann* \\ Koch Institute for Integrated Cancer Research at MIT, Cambridge, Massachusetts, United States of America \\ * hemann@mit.edu
}

\section{Abstract}

Aberrant chromatin regulation is a frequent driver of leukemogenesis. Mutations in chromatin regulators often result in more stem-like cells that seed a bulk leukemic population. Inhibitors targeting these proteins represent an emerging class of therapeutics, and identifying further chromatin regulators that promote disease progression may result in additional drug targets. We identified the chromatin-modifying protein CHD8 as necessary for cell survival in a mouse model of BCR-Abl+B-cell acute lymphoblastic leukemia. This disease has a poor prognosis despite treatment with kinase inhibitors targeting BCR-Abl. Although implicated as a risk factor in autism spectrum disorder and a tumor suppressor in prostate and lung cancer, the mechanism of CHD8's activity is still unclear and has never been studied in the context of hematopoietic malignancies. Here we demonstrate that depletion of CHD8 in B-ALL cells leads to cell death. While multiple B cell malignancies were dependent on CHD8 expression for survival, T cell malignancies displayed milder phenotypes upon CHD8 knockdown. In addition, ectopic expression of the Notch1 intracellular domain in a T cell malignancy partially alleviated the detrimental effect of $\mathrm{CHD} 8$ depletion. Our results demonstrate that $\mathrm{CHD} 8$ has a context-dependent role in cell survival, and its inhibition may be an effective treatment for $B$ lymphoid malignancies.

Copyright: @ 2015 Shingleton, Hemann. This is an open access article distributed under the terms of the Creative Commons Attribution License, which permits unrestricted use, distribution, and reproduction in any medium, provided the original author and source are credited.

Data Availability Statement: All relevant data are within the paper and its Supporting Information files.

Funding: This work was funded by the Ludwig Foundation for Cancer research (http://www. ludwigcancerresearch.org). JRS was funded by by an NSF graduate Fellowship. The funders had no role in study design, data collection and analysis, decision to publish, or preparation of the manuscript.

Competing Interests: The authors have declared that no competing interests exist.

\section{Introduction}

Philadelphia-chromosome positive acute lymphoblastic leukemia (Ph+B-ALL) accounts for approximately $20 \%$ of adult cases of leukemia in the United States [1]. This disease has a poor prognosis despite the development of multiple inhibitors targeting the BCR-Abl fusion tyrosine kinase that drives this disease. Patients initially respond well to tyrosine kinase inhibitors (TKIs) but quickly relapse, usually acquiring resistance due to mutations in the $\mathrm{Abl}$ kinase domain that prevent TKI binding, upregulation of drug efflux pumps, or activation of alternative signaling pathways such as SRC family kinases [2-4]. Our group previously performed a large-scale RNAi screen in a mouse model of this disease to identify factors that promote cell survival in Ph+ B-ALL and could serve as novel drug targets [5]. This model expresses a human $B C R-A b l$ transgene and a disrupted $p 19^{A R F}$ locus, closely recapitulating the genetics of the human disease as approximately $50 \%$ of $\mathrm{Ph}+\mathrm{B}$-ALL patients exhibit loss-of-function of the 
$\mathrm{CDKN} 2 \mathrm{~A} / \mathrm{B}$ locus that contains $p 19^{A R F}[6,7]$. In addition, most cells can give rise to disease in transplant experiments [6], so this model is able to represent a highly complex RNAi library in vivo.

Among the list of screening hits were shRNAs targeting chromatin modifiers with established roles in cancer such as $\operatorname{Sin} 3 a$, underscoring the importance of epigenetic regulation in leukemia progression. Inhibitors of chromatin modifiers represent an emerging class of therapeutics that holds great potential, and recent work has suggested that inhibiting these enzymes could help circumvent acquired resistance to existing drugs [8-10]. Another chromatin modifier that arose as a candidate hit in this screen was Chd8. Chd8 has been associated with autism spectrum disorder as well as cancer, but its mechanism of action is not well understood [1117]. Several roles in transcriptional regulation and target gene sets have been proposed, but a consensus on the precise function of CHD8 has yet to emerge.

CHD8 was discovered in a yeast two-hybrid screen as a $\beta$-catenin binding partner that inhibits transcription of $\beta$-catenin target genes [18]. A proposed role of CHD8 is negative regulation of $\mathrm{p} 53$ and Wnt pathway activity through chromatin compaction at target genes during early embryonic development $[19,20]$. Other studies have demonstrated a role of CHD8 in cell cycle regulation including promoting transcription of E2F target genes involved in the G1/S transition [21,22].

While multiple groups have measured higher CHD8 expression in cancer cells than normal adult tissue [19,23], other groups have observed loss of expression in gastric and colorectal cancers and deletion in lung cancer $[15,16,24]$. It is intriguing that CHD8 appears to act in a proproliferative or pro-survival manner in most contexts but as a tumor suppressor in other malignancies, perhaps through inhibition of Wnt signaling. Further investigation is needed to determine the context in which CHD8 inhibition would be detrimental to the tumor and thus advantageous to patients. For this reason we pursued further investigation into the pro-survival function of CHD8 in BCR-Abl+ B-ALL cells.

We characterized Chd8 as a pro-survival gene in this model of BCR-Abl+ B-ALL, confirming the RNAi screening results. Depletion of CHD8 resulted in cell death, but without a preceding cell cycle arrest. Interestingly, we found differing requirements for CHD8 expression between B and T cell malignancies. T-ALL cells expressing the intracellular domain of Notch (ICN) were less dependent on CHD8 expression, and ectopic expression of ICN in K-ras driven T-cell lymphoma cells partially rescued the dependency of these cells on CHD8 expression. We conclude that CHD8 is a context-dependent pro-survival factor, and that constitutive Notch signaling is able to compensate for CHD8 loss through mechanisms that are not yet fully understood.

\section{Materials and Methods Cell Culture}

BCR-Abl+ B-ALL and Top Notch T-ALL cells were cultured in RPMI-1640 (HyClone) with $10 \%$ fetal bovine serum (FBS), $5 \mu \mathrm{M} \beta$-mercaptoethanol, and $4 \mathrm{mM}$ L-glutamine. Eu-myc Arf ${ }^{\prime}$ cells were cultured in 45\% DMEM/45\% IMDM (HyClone) with 10\% FBS, $5 \mu \mathrm{M} \beta$-mercaptoethanol, and $2 \mathrm{mM}$ L-glutamine. $K$-ras ${ }^{L A 2 /+} ; p 53^{L S L / L S L} \mathrm{~T}$ cell lymphoma cells were cultured in IMDM with $10 \%$ FBS and $10 \mu \mathrm{M} \beta$-mercaptoethanol. Pre-B cells were harvested from bone marrow of a C57BL/6 mouse, stained with fluorescently-conjugated anti-B220 (BioLegend), anti-CD11b (eBioscience), and anti-IgM antibodies (eBioscience) and sorted to obtain B220 $0^{+-}$

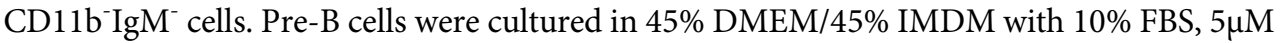
$\beta$-mercaptoethanol, $2 \mathrm{mM} \mathrm{L}$-glutamine, recombinant murine IL-7 $(1.0 \mathrm{ng} / \mathrm{mL})$, and recombinant murine SCF $(1.0 \mathrm{ng} / \mathrm{mL})$ (Peprotech) on a feeder layer of bone marrow stromal cells. 


\section{shRNAs and plasmids}

shRNAs were designed and cloned as previously described [25]. Oligo sequences (S1 Table) were PCR-amplified with primers containing XhoI and EcoRI restriction sites (S2 Table). shRNAs were cloned into MSCV/LTRmir30-PGK-puromycin ${ }^{\mathrm{r}}$-IRES-GFP (MLP) or MSCV/ LTRmir30-SV40-GFP (MLS) for GFP competition assays, and TRMPVIR (TRE-dsRedmiR30/shRNA-PGK-Venus-IRES-rtTA3) for inducible shRNA studies [26]. pMIG (MSCV-IRES-GFP, Addgene 9044) and pMIG-ICN were used for rescue assays. Duplin was cloned using the Gibson Assembly ${ }^{\circledR}$ method (New England BioLabs). mRNA was extracted from B-ALL cells using a Qiagen RNEasy kit and reverse-transcribed with the ThermoScript RT-PCR system (Life Technologies). cDNA was PCR-amplified with Phusion polymerase (New England BioLabs) with primers flanking the Duplin sequence and containing Gibson Assembly ${ }^{\circledR}$ overhang sequences (S2 Table). The PCR product was ligated into modified pMIG (Not1 and Mfe1 sites inserted between EcoRI and XhoI restriction sites using oligos listed in S2 Table). To generate retroviruses, 293T cells were transfected with plasmids using the calcium phosphate method [27].

\section{CRISPR-Cas9}

Single-guide RNA sequences (S3 Table) were designed and cloned into pSpCas9(BB)-2A-GFP according to the protocol in Ran et al [28]. tdTomato+ B-ALL cells were transfected using Lipofectamine 3000 (Life Technologies) according to the manufacturer's protocol. Cells were sorted 24 hours later by GFP expression, either into 96-well plates as single cells, or into tubes and seeded into 96-well plates as single cells 3 days later. Clonal populations were analyzed for CHD8 expression by western, and editing of the Chd8 gene by sequencing (PCR and sequencing primers listed in $\mathrm{S} 2 \mathrm{Table}$ ). For growth competition assays, clonal populations were mixed with unlabeled control B-ALL cells and seeded in triplicate. Percentages of tdTomato+ cells were analyzed 2, 4, and 8 days later by flow cytometry. Clones Chd8-1 and - 2 were generated with sgChd8-2, clone Chd8-4 was generated with sgChd8-3, and clones Chd8-3 and Chd8-5 were generated with sgChd8-4. Clones Ren- 1 and -2 were generated with sgRen-2, and clone Ren-3 was generated with sgRen-3.

\section{Western blotting and qPCR}

Cell pellets were generated following puromycin selection (MLP) or doxycycline treatment of sorted cells (TRMPVIR). $\mathrm{K}-\mathrm{ras}^{\mathrm{LA2/+}} ; \mathrm{p} 53^{\text {LSL/LSL }}$ cells were sorted following transduction with MLS. Lysates were generated using RIPA buffer. Antibodies and dilutions are listed in S4 Table. mRNA for qPCR analysis was extracted using a Qiagen RNEasy kit and reverse-transcribed with MMLV-RT (New England BioLabs). qPCR primer sequences are listed in S5 Table. qPCR was performed using Fast SYBR ${ }^{\circledR}$ Green Master Mix and a StepOnePlus ${ }^{\mathrm{TM}}$ RealTime PCR System (Applied Biosystems).

\section{Growth competition assays and survival experiments}

Cells were partially infected with the indicated retroviruses and seeded in 6-well plates in triplicate. Percentages of GFP+ cells were determined by flow cytometry on days 2, 6, and 10 after infection. For in vivo competition assays, $2 \times 10^{6}$ partially infected cells were injected into female C57BL/6 (6-8 week old) mice via the tail vein. Upon disease presentation, leukemic cells were harvested from the spleen, bone marrow, and peripheral blood and analyzed by flow cytometry to determine percentages of GFP+ cells. Propidium iodide incorporation was used to exclude dead cells. For survival experiments, cells transduced with the indicated constructs were sorted 
by GFP expression and approximately $20 \mathrm{GFP}+$ cells per mouse (female C57BL/6, 6-8 weeks old) were injected via the tail vein. Upon disease presentation, cells were harvested from the spleen and peripheral blood and analyzed by flow cytometry to determine percentages of GFP+ cells. All mice were sourced from Jackson Laboratories.

\section{Growth curves and cell cycle analysis}

Cells were infected with MLP, MLP-shChd8-0, or MLP-shChd8-1 and selected with puromycin. Indicated numbers of live cells were seeded in triplicate, and total numbers of live and dead cells were counted at the indicated time points by hemocytometer and trypan blue incorporation. For cell cycle analysis, B-ALL cells were infected with TRMPVIR-shRen or TRMPVIR-shChd8-1 and sorted by Venus expression. Sorted cells were plated and treated with doxycycline (Sigma, $200 \mathrm{ng} / \mathrm{mL}$ ), and samples were collected at indicated time points and fixed in ethanol. Cells were stained with propidium iodide and analyzed by flow cytometry. Cell cycle profiles were created with ModFit LT software (Verity Software).

\section{Statistical analysis}

Student's $t$ tests, ANOVA, and survival analyses were performed with GraphPad Prism software.

\section{Ethics Statement}

This study was carried out in accordance with the recommendations in the Guide for the Care and Use of Laboratory Animals of the NIH. The protocol was approved by the MIT Committee on Animal Care (Protocol \#0515-044-18). All efforts were made to minimize suffering. In long-term survival experiments, animals were monitored 3 times per week for two weeks (a time-frame established by prior experiments with this disease model), then daily as animals in the control cohort developed disease. Animals were euthanized when symptoms (hunched posture, lower levels of activity) were displayed. There were no unexpected animal deaths.

\section{Results}

\section{CHD8 depletion is detrimental to growth of BCR-Abl+ B-ALL cells in vitro and in vivo}

To validate that the deleterious effect of the original shRNA targeting Chd8 in the screen is due to knockdown of the intended target, additional constructs targeting Chd8 were designed and tested by GFP competition assays (Fig 1A). In these assays, a population of cells is partially transduced with a retroviral vector expressing an shRNA linked to a GFP marker to allow identification of shRNA-expressing cells by flow cytometry. As with the original shRNA identified by the screen, an additional shRNA also led to a significant decrease in CHD8 expression at the protein level (Fig 1B). Consistent with an on-target effect, both constructs led to depletion of transduced B-ALL cells over time, both in in vitro and in vivo settings (Fig 1C and 1D). Depletion of shChd8-expressing leukemic cells was observed in all lymphatic tissues examined (spleen, bone marrow, and peripheral blood). These results indicate that the detrimental effects of CHD8 knockdown are cell-autonomous and independent of the tumor microenvironment. Interestingly, while shChd8-0 appears to confer its deleterious phenotype more rapidly than shChd8-1 in vitro, cells expressing shChd8-1 deplete to a similar extent when examined over a longer period of time (S1 Fig).

The model of BCR-Abl+ B-ALL utilized in this study is very aggressive, giving rise to terminal disease in less than two weeks following tail vein injection of 2 million cells into 

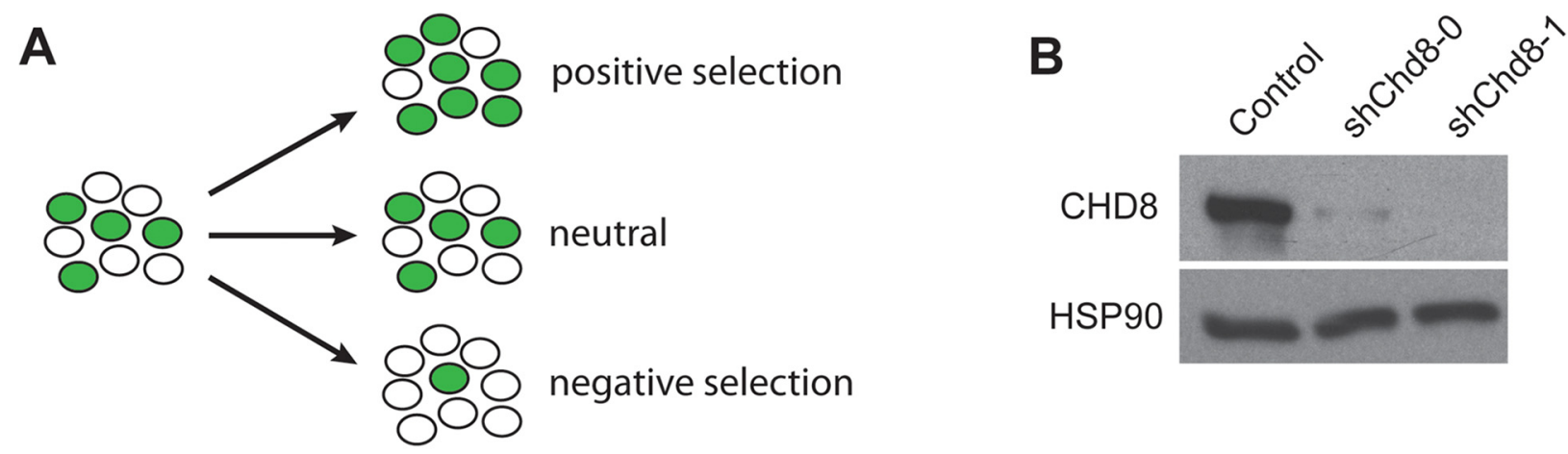

Fold Change $=\frac{\% \text { GFP }+ \text { Cells }(\text { Final) }}{\% \text { GFP+ Cells (Initial) }}$

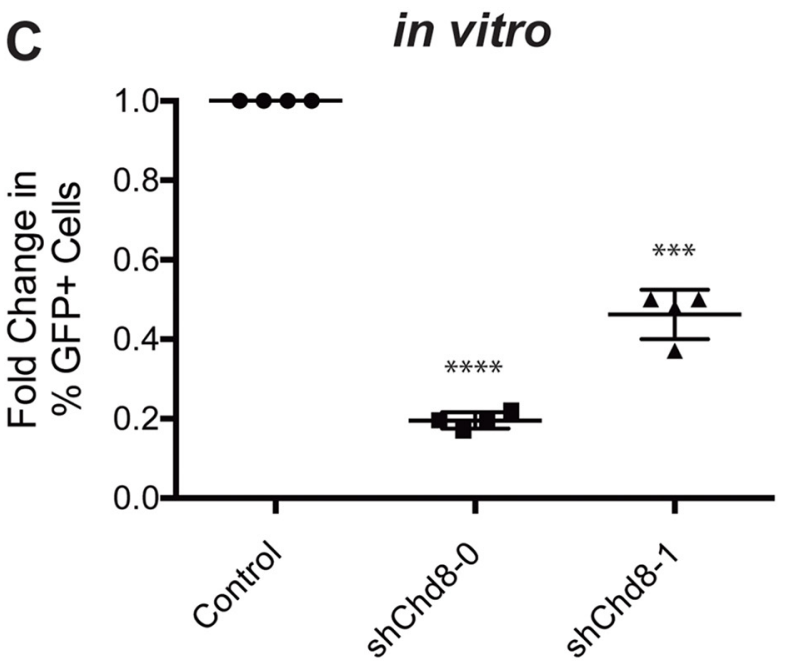

D
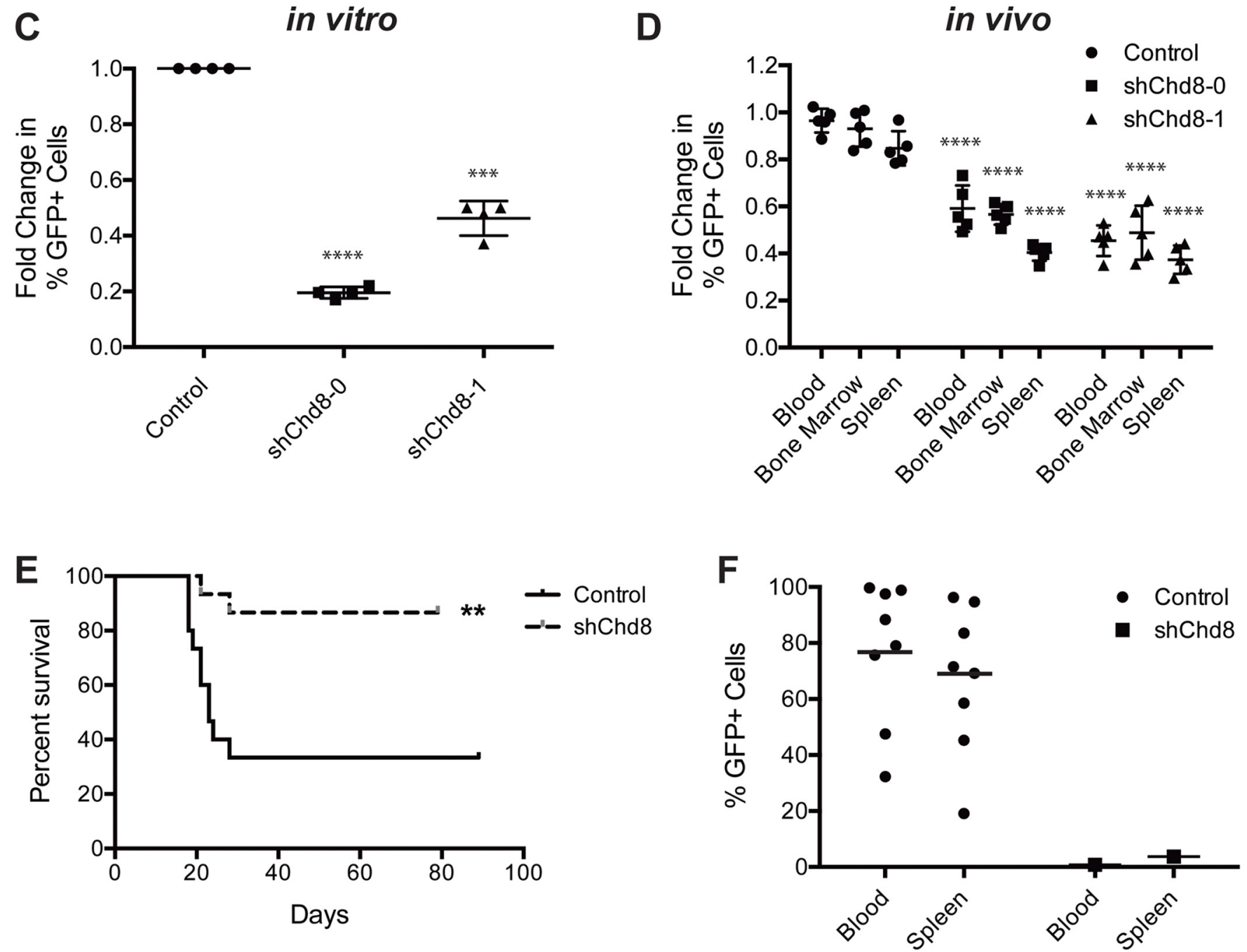

Fig 1. CHD8 depletion by RNAi is detrimental to B-ALL cells in vitro and in vivo. (A) Schematic of the GFP growth competition assay. An increase in the percentage of GFP+ cells indicates positive selection conferred by shRNA expression, while a decrease indicates negative selection. (B) Western blot showing decreased CHD8 expression in B-ALL cells conferred by both shRNAs (4 days following retroviral infection). (C, D) Results of in vitro (C) and in vivo (D) growth competition assays. Shown are averages \pm SEM of four independent experiments (C) and averages \pm SD of 5 mice (D). Fold changes of in vitro 
assays were calculated from day 2 to day 10 after retroviral infection and normalized to an empty vector control. Fold changes of in vivo assays were calculated from day 2 after retroviral infection (day of injection) to morbidity (approximately 10 days later). In vivo assay shRNA results were compared with empty vector control in each respective tissue. (E) Kaplan-Meier curve showing survival of mice injected with B-ALL cells transduced with the indicated constructs. $n=15$ per cohort. (F) Graph showing GFP expression of cells harvested from the indicated mice upon morbidity. ${ }^{*} P<0.005$, ${ }^{* * *} P=0.002$, ****P<0.0001

doi:10.1371/journal.pone.0143275.g001

immunocompetent syngeneic mice. We predicted that CHD8 depletion in transplanted B-ALL cells would increase time to disease due to attenuation of cell viability and tumor growth. Cells expressing shChd8-1 or a GFP vector control were sorted to obtain pure GFP+ populations. Very low numbers of cells were transplanted by tail vein injection into each of $30 \mathrm{C} 57 \mathrm{BL} / 6$ mice (15 per cohort), and time to morbidity was monitored. Time to terminal disease was indeed extended significantly in mice injected with CHD8-depleted cells (Fig 1E). Disease penetrance was decreased as well, with only 2 mice in the shChd8-1 cohort succumbing to disease, compared with 10 mice in the control cohort. When mice reached morbidity, cells from the spleen and peripheral blood were collected and analyzed by flow cytometry for GFP expression. Interestingly, cells collected from mice in the control cohort were polyclonal and expressed GFP, but cells harvested from mice injected with CHD8-depleted cells were GFP-negative (Fig 1F). These results indicate that disease onset in these mice was caused by the outgrowth of a small number of GFP-negative cells contaminating the injected population.

As additional confirmation that the detrimental effects of these shRNAs are due to depletion of CHD8, we performed gene editing using the CRISPR-Cas9 system. B-ALL cells expressing the tdTomato fluorophore were transfected with one of three single-guide sequences cloned into a CRISPR-Cas9 vector. Single cell clones were generated and tested for gene editing and loss of CHD8 protein expression (Figs 2A and S2). These cells were mixed with unlabeled control B-ALL cells to carry out in vitro growth competition assays. We observed depletion of tdTomato+, Chd8-edited B-ALL cells relative to control cells in these assays, confirming that loss of CHD8 is detrimental (Fig 2B). In contrast, B-ALL cells transduced with guide sequences targeting Renilla luciferase, which is not expressed in these cells, expressed normal levels of CHD8 (S3 Fig) did not deplete in similar growth competition assays (Fig 2B). In addition, mice were injected with low numbers of B-ALL cells grown from these CHD8-deficient or control clonal populations (10 mice per cohort). All 20 mice injected with control B-ALL cells succumbed to disease by Day 39 after injection, but only 6 out of 40 mice injected with cells deficient for CHD8 developed disease within 11 weeks of injection (Fig 2C).

\section{An inducible RNAi vector allows examination of gene function in a temporally controlled manner}

In order to study the downstream molecular effects of Chd8 knockdown in a temporally controlled manner, an shRNA targeting Chd8 was cloned into the doxycycline-inducible retroviral vector TRMPVIR [26]. This vector utilizes a Tet-On system to control transcription of an shRNA. A reverse Tet-transactivator (rtTA) and the Venus fluorophore are constitutively expressed, and addition of doxycycline induces expression of the shRNA as well as a dsRed marker, creating a population of Venus ${ }^{+} \mathrm{dsRed}^{+}$cells (Fig 3A). When transduced into B-ALL cells, TRMPVIR-shChd8-1 leads to a marked reduction of CHD8 expression by 12 hours following treatment with doxycycline, while CHD8 levels in cells transduced with TRMPVIR expressing a Renilla luciferase shRNA (shRen) are not affected (Fig 3B). 
A

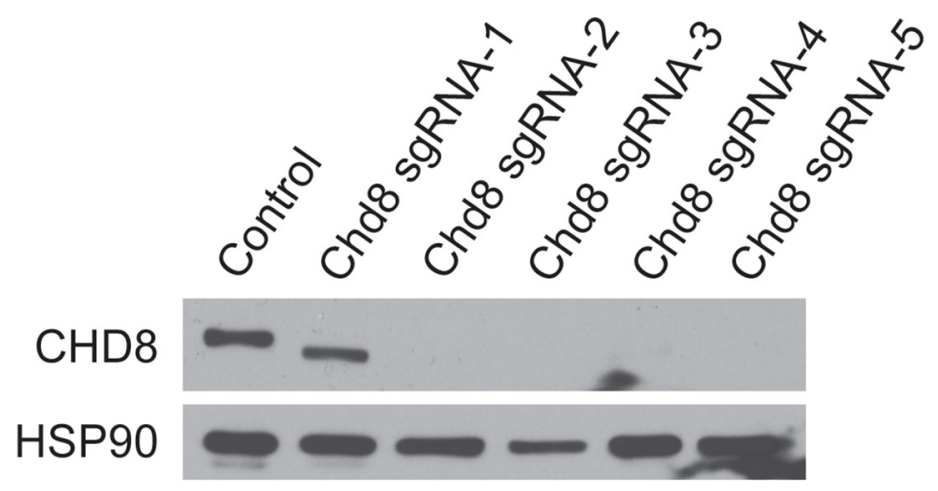

B
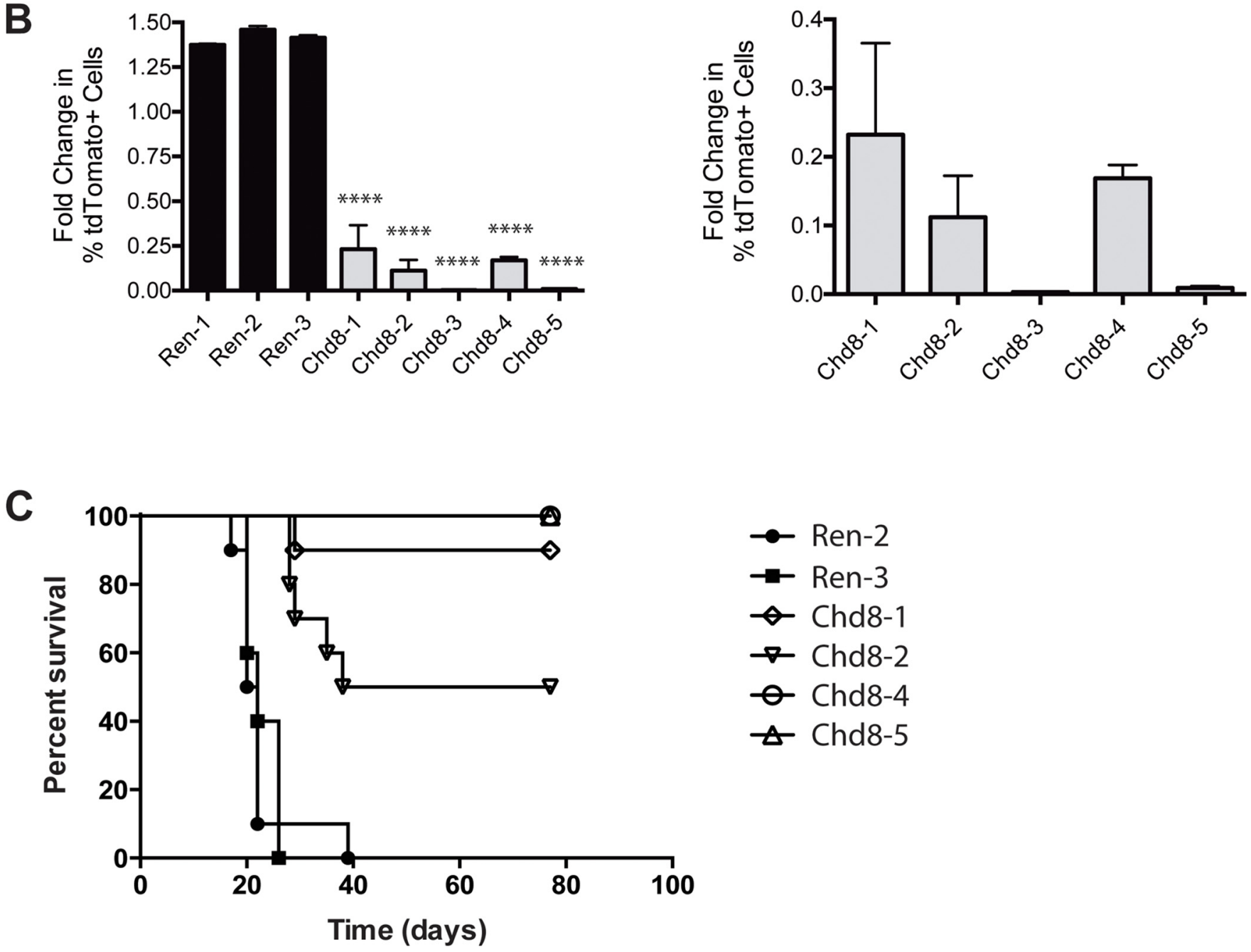

Fig 2. CRISPR-Cas9 editing of CHD8 is detrimental to B-ALL cells. (A) Western blot showing loss of CHD8 expression or expression of a truncated protein following gene editing by CRISPR-Cas9 in B-ALL cells. Expression of truncated protein likely arises from an ORF in original reading frame following a new stop codon generated by gene editing. Chd8 sgRNA-1 and -2 cell lines were generated with sgChd8-2 construct, Chd8 sgRNA-4 was generated with sgChd8-3 construct, and Chd8 sgRNA-3 and -5 were generated with sgChd8-4 construct. (B) (Left) Bar graph showing results of in vitro growth competition assays with B-ALL cells following gene editing by CRISPR-Cas9. Constructs targeting Renilla luciferase (Ren) were used as negative controls. Ren-1 and -2 cell lines were generated using sgRen-2 construct, and Ren-3 was generated using sgRen-3 construct. Shown are averages \pm SD. (Right) Detailed bar graph showing results of in vitro growth competition assays. (C) Kaplan-Meier curve showing survival of mice injected with B-ALL cells transduced with the indicated constructs. $\mathrm{n}=10$ per cohort. See S6 Table for statistics. ${ }^{* * *} \mathrm{P}<0.0001$

doi:10.1371/journal.pone.0143275.g002 
A

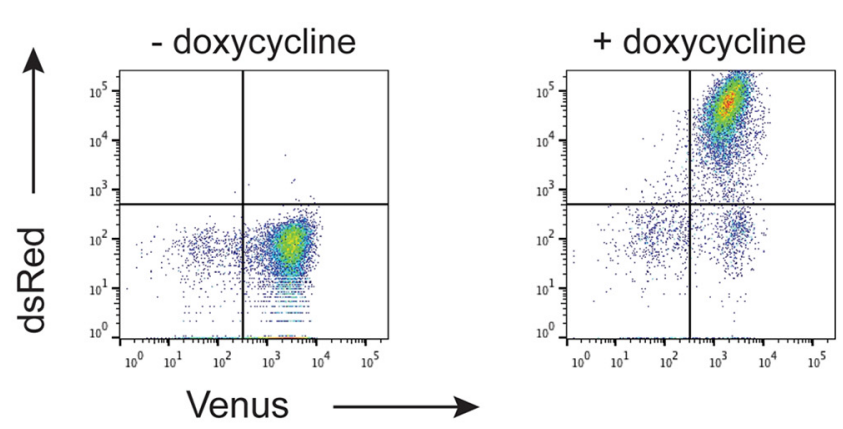

B

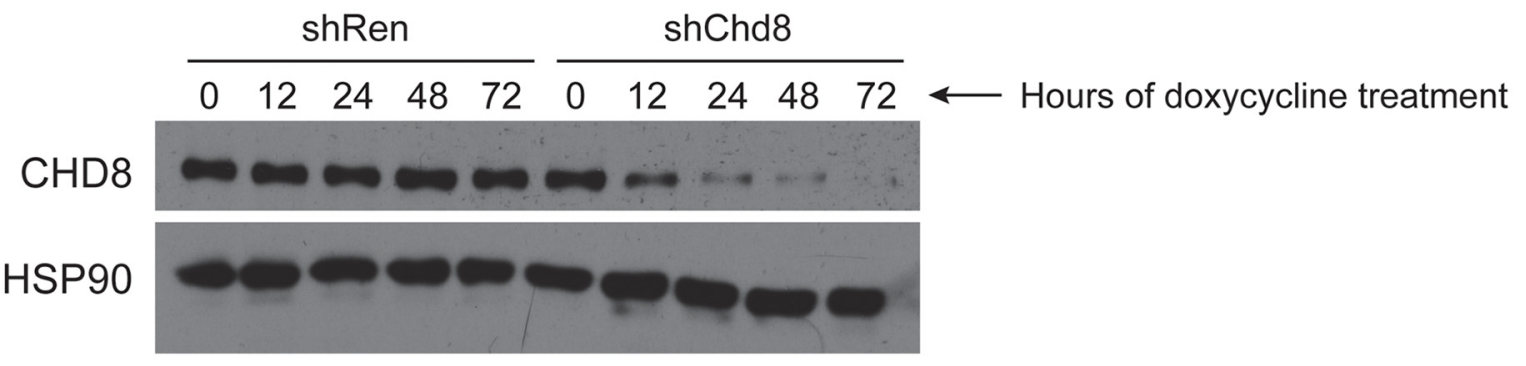

C

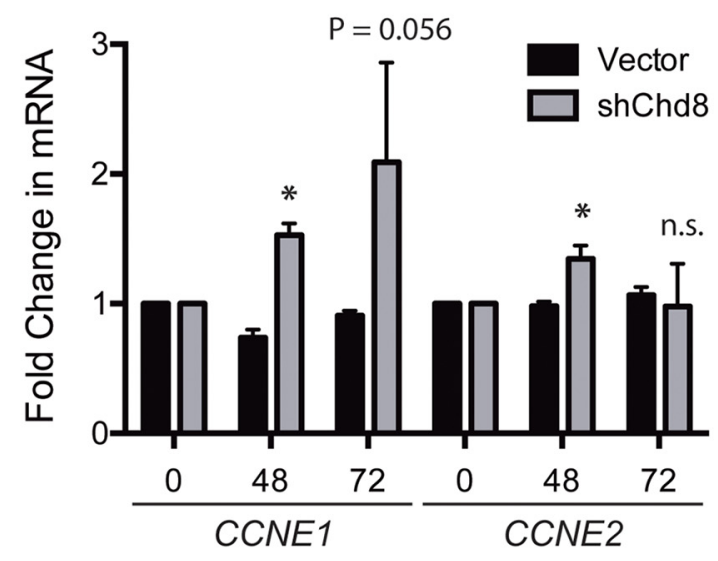

E

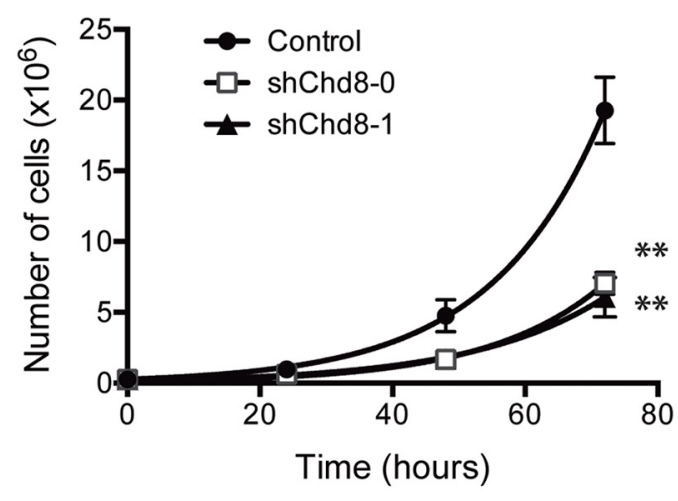

D

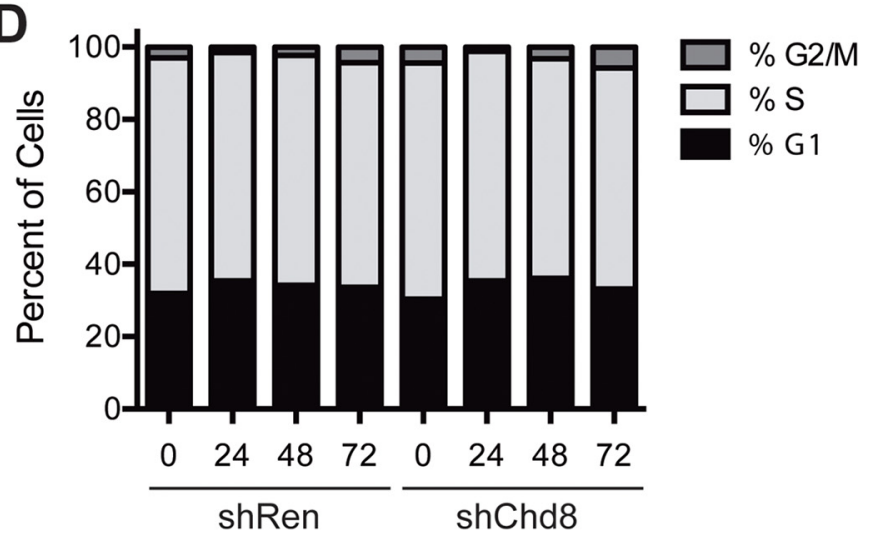

$\mathbf{F}$

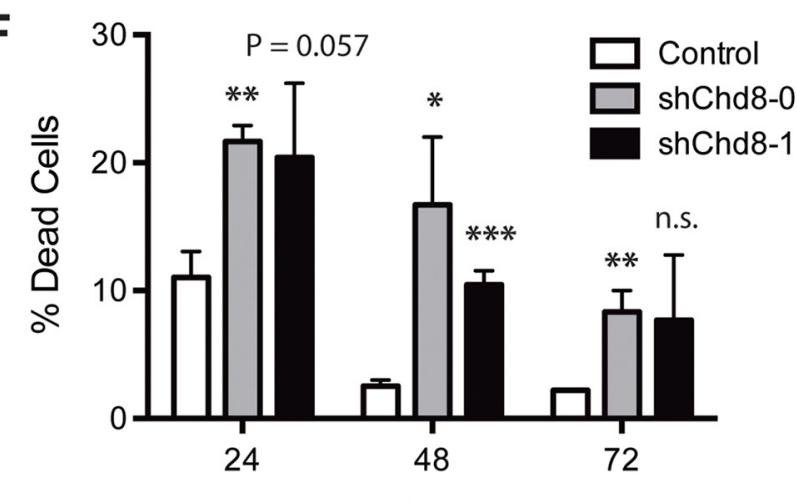

Hours 
Fig 3. CHD8 knockdown in B-ALL cells leads to cell death without a cell cycle arrest. (A) Flow cytometry plots showing induction of dsRed and a linked shRNA upon treatment with doxycycline. (B) Western blot showing decreased CHD8 expression over time following induction of shChd8 in B-ALL cells by doxycycline. (C) Bar graph showing increased CCNE1 and CCNE2 expression upon CHD8 knockdown. Shown are averages \pm SD. (D) Bar graph showing cell cycle profiles of B-ALL cells following shRNA induction by doxycycline. (E) Graph showing growth rates of B-ALL cells transduced with the indicated constructs. Shown are averages \pm SD. (F) Bar graph showing percentages of dead cells following Chd8 knockdown. Survival of cells transduced with shChd8 may be due to selection against CHD8 knockdown. Shown are averages $\pm \mathrm{SD}$. ${ }^{*} \mathrm{P}<0.01,{ }^{*} \mathrm{P}<0.005,{ }^{*} * \mathrm{P}<0.0005$

doi:10.1371/journal.pone.0143275.g003

\section{CHD8 depletion leads to cell death without a preceding cell cycle arrest}

Others have found that CHD8 depletion leads to a decrease in expression of CCNE2 and TYMS and a subsequent cell cycle arrest at the G1/S transition [21]. We examined CCNE2 as well as CCNE1 expression by qPCR in B-ALL cells expressing TRMPVIR-shChd8-1 or the shRen control. Surprisingly, mRNA expression levels of CCNE1 and CCNE2 were found to be slightly higher in CHD8-depleted cells after 48 hours of doxycycline (Fig 3C). This result seemed counter to the expected outcome in that a decrease in cyclin expression rather than an increase would be expected to be detrimental to cell cycle progression. To determine if this change in CCNE1 and CCNE2 levels correlated with a change in cell cycle profile, cell cycle analysis was carried out on these populations. Flow cytometry analysis revealed no significant change in the cell cycle profile upon CHD8 depletion (Fig 3D), indicating that dysregulation of CCNE1 and CCNE2 transcription upon CHD8 depletion does not lead to a G1/S arrest in B-ALL cells.

However, these results do not preclude the possibility that CHD8 depletion leads to a prolonged doubling time in these cells, lengthening each stage of the cell cycle rather than arresting in a particular stage. CHD8 depletion could also lead to cell death without a preceding cell cycle arrest. To test this possibility, we retrovirally infected cells with a puromycin-selectable vector expressing one of two shChd8 constructs or a vector control. Following puromycin selection, $2.5 \times 10^{5}$ live cells per construct were plated in triplicate, and the total numbers of live and dead cells were quantified at 24 -hour intervals. Both shChd8 constructs caused a decrease in the apparent growth rates of B-ALL cells and an increase in the percentages of dead cells (Fig $3 \mathrm{E}$ and 3F). Taken together, these results argue that the depletion of shChd8-expressing cells observed in the growth competition assays is due to cell death rather than slowed proliferation.

Notably, this death may not be due to canonical apoptosis as treatment with the pan-caspase inhibitor ZVAD-fmk simultaneously with doxycycline did not prevent CHD8 knockdownmediated cell death an in in vitro growth competition assay ( 55 Fig). In addition, no evidence of caspase 3 cleavage was seen by western blot at $12,24,48$, or 72 hours after doxycycline treatment (S6 Fig).

\section{Ectopic expression of CHD8 N-terminal domains}

Given that a number of CHD8 domains have been shown to interact with specific binding partners including p53, $\beta$-catenin, CTCF, and methylated H3K4 $[19,20,29]$, we reasoned that determining the domains necessary for CHD8 function in B-ALL cells might inform important prosurvival roles. Previously, others have found that overexpression of a $110 \mathrm{kDa}$ truncated N-terminal isoform of murine CHD8 called Duplin was able to rescue cells from p53-mediated apoptosis as effectively as full-length CHD8 [19]. Duplin contains the first of the two chromodomains in CHD8, but not other identified functional domains [20,29]. We hypothesized that overexpression of this truncated isoform might be able to rescue the shChd8 phenotype in B-ALL cells. Duplin cDNA was PCR-amplified from B-ALL cDNA and cloned into an MSCV-IRES-GFP ( $\mathrm{pMIG}$ ) retroviral vector. Transduction of B-ALL cells with pMIG-Duplin led to high expression of the protein as expected, however endogenous expression of Duplin 
was not observed in untransduced cells (Fig 4A). Previous studies did not measure Duplin expression in blood, so it is possible that only the full-length isoform is expressed in murine lymphoid cells. However, we were also unable to detect expression of multiple isoforms of Chd 8 by qPCR in other murine tissues including brain, liver, lung, and kidney (Fig 4B).

Although this isoform may not normally be expressed, we reasoned that if the domains found in Duplin are important for CHD8 function in B-ALL cells, Duplin overexpression would still be able to prevent depletion of shChd8-expressing cells in growth competition assays. shChd81 was selected for use in rescue experiments as it is specific for the full-length isoform. As seen in Fig 4C, exogenous expression of Duplin was unable to prevent depletion of shChd8-expressing cells, suggesting that the domains found in Duplin are not sufficient to rescue the effects of CHD8 depletion. While a full-length cDNA control that does rescue the CHD8 knockdown phenotype would make these results more conclusive, the large size of this cDNA (7.75 kb) made it challenging to clone and express in B-ALL cells despite several attempts.

\section{Untransformed pre-B cells require CHD8 for survival}

Previously, it had been observed that CHD8 is overexpressed in murine cancer cell lines compared to corresponding normal tissues [20]. To determine if this pattern could be observed in the B-cell lineage, bone marrow was harvested from healthy adult C57BL/6 mice, and pre-B cells (B220 $\left.\mathrm{IgM}^{-} \mathrm{CD} 11 \mathrm{~b}^{-}\right)$were collected by flow cytometry. Unexpectedly, CHD8 expression in these untransformed pre-B cells was comparable to that seen in B-ALL cells (Fig 5A). The dependence of these cells on CHD8 expression was also tested by a growth competition assay in vitro. While protein expression levels in these cells may be similar, biological differences between the cell types might make untransformed pre-B cells less reliant on CHD8 for survival. However, untransformed pre-B cells expressing shChd8 depleted in vitro to a similar extent as B-ALL cells, indicating that in the B lymphoid lineage dependence on CHD8 expression is not limited to malignant cells (Fig 5B).

\section{Differential requirement for CHD8 expression in hematopoietic malignancies}

While CHD8 expression is required in untransformed pre-B cells, malignancies with different genetic backgrounds or within different developmental contexts may have mechanisms that allow cell survival in the absence of this protein. We reasoned that identifying a context-specific survival requirement could shed light on CHD8 function. To determine whether dependency on CHD8 extends to other hematopoietic malignancies, we first tested another cancer of the B cell lineage, a murine model of Burkitt's lymphoma. In this model, c-myc is under the transcriptional control of the $\mu$ immunoglobulin heavy chain enhancer $(\mathrm{E} \mu-m y c)$, mimicking the $t$ $(8 ; 14)(\mathrm{q} 24 ; \mathrm{q} 32)$ chromosomal translocation that causes this disease in humans [30-32]. We transduced these cells with shRNAs targeting $C h d 8$ and confirmed decreased protein expression by western blot (Fig 5C). As with BCR-Abl+ B-ALL cells, E $\mu$-myc cells expressing these shRNAs deplete in in vitro growth competition assays (Fig 5D), and pure populations of shRNA-expressing cells display decreased proliferation rates and increased numbers of dead cells compared with cells expressing vector controls (Fig 5E and 5F).

A recent study into vulnerabilities of drug-resistant T-ALL cells uncovered a number of epigenetic regulators that became essential upon acquisition of drug resistance [8]. CHD8 was one of several epigenetic regulators found to be preferentially required for survival by $\gamma$-secretase inhibitor (GSI)-resistant cells over syngeneic, GSI-sensitive cells. These resistant cells exhibited a lower level of Notch signaling than the sensitive population, suggesting that high Notch pathway activity may somehow compensate for CHD8 loss. In agreement with these results, we 
A

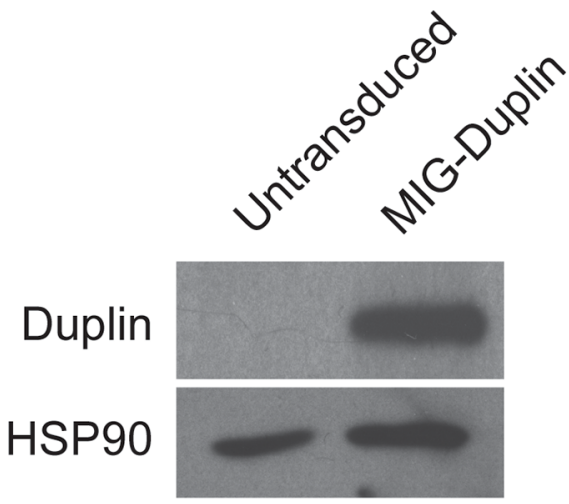

B

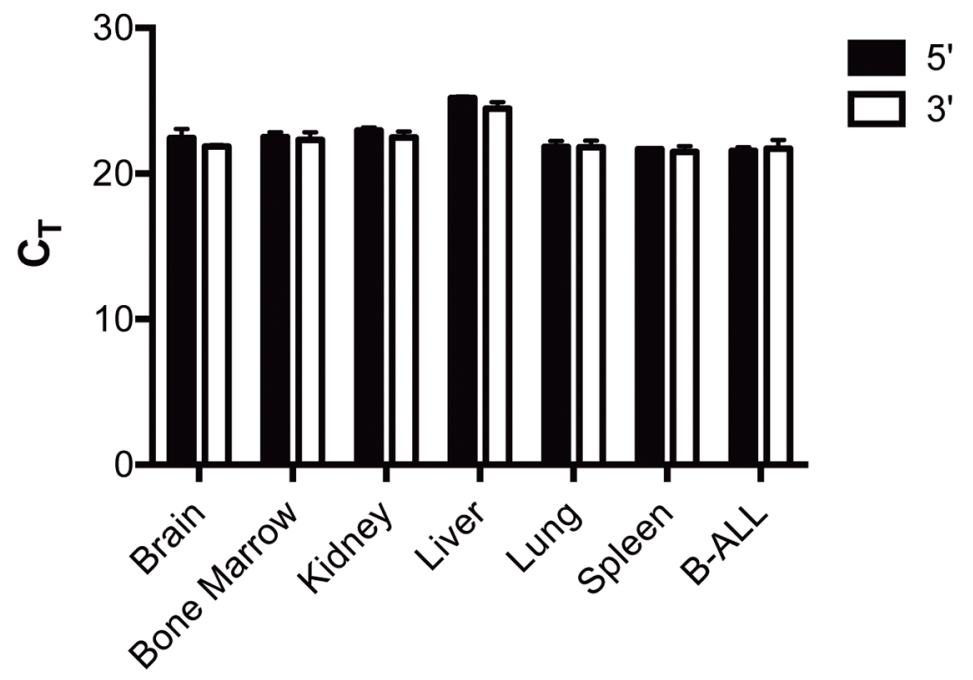

C

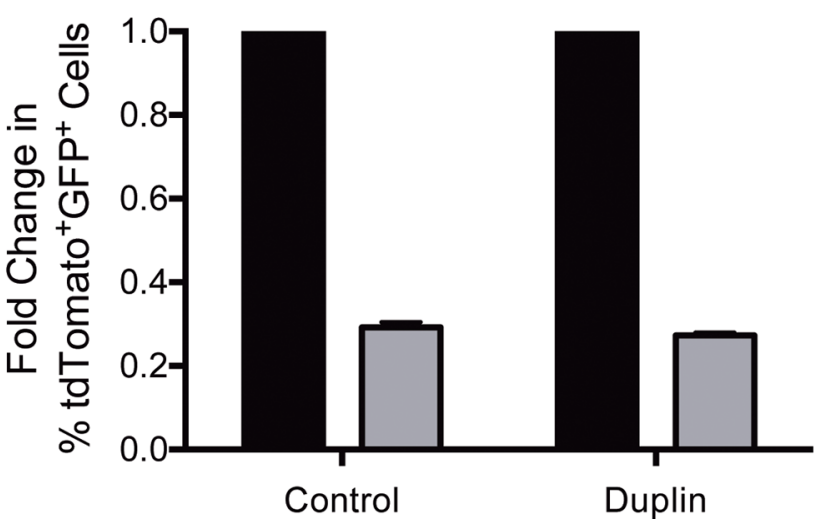

Control

shChd8-1

Fig 4. Duplin expression does not rescue shChd8 phenotype in B-ALL cells. (A) Western blot showing Duplin expression in B-ALL cells transduced with MIG-Duplin, but not untransduced cells. (B) Bar graph showing $C h d 8 \mathrm{C}_{\mathrm{T}}$ values in the indicated mouse tissues with the indicated qPCR primer pairs. Shown are averages \pm SD. (C) Bar graph showing depletion of shChd8-expressing B-ALL cells transduced with MIG-Duplin or a GFP vector control. Shown are averages normalized to vector control \pm SD. Fold changes were calculated from day 2 to day 10 after second retroviral infection and normalized to MLT (tdTomato) empty vector control.

doi:10.1371/journal.pone.0143275.g004 
A

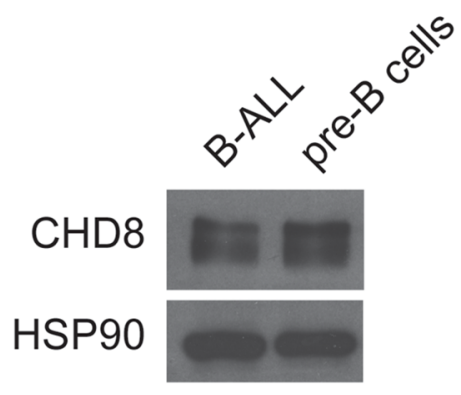

C

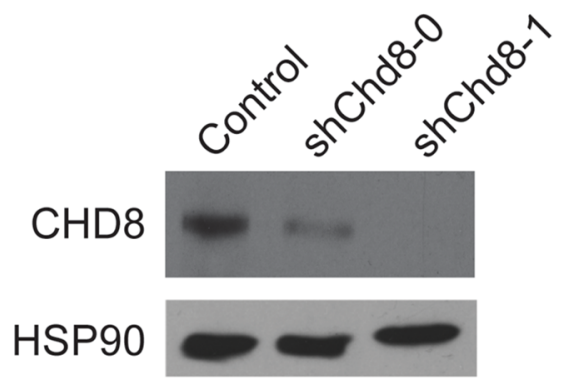

E

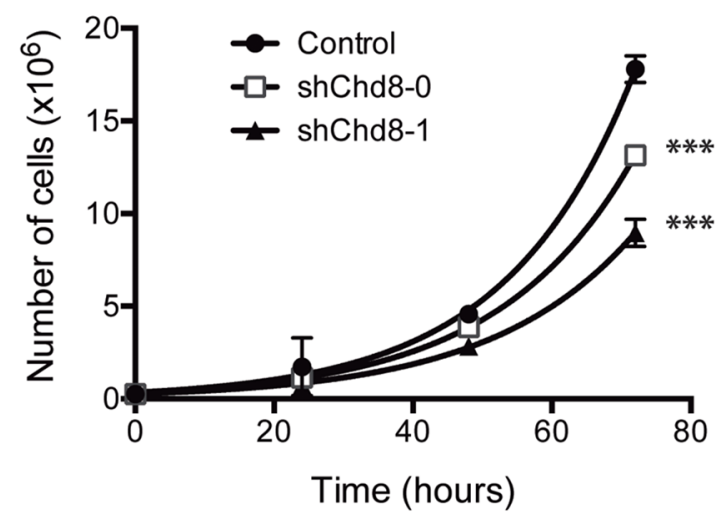

B

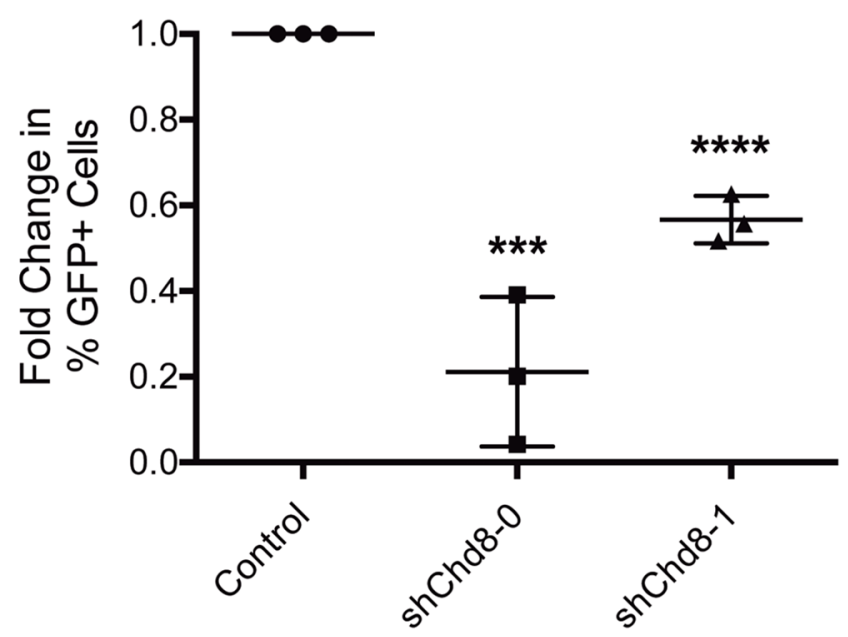

D

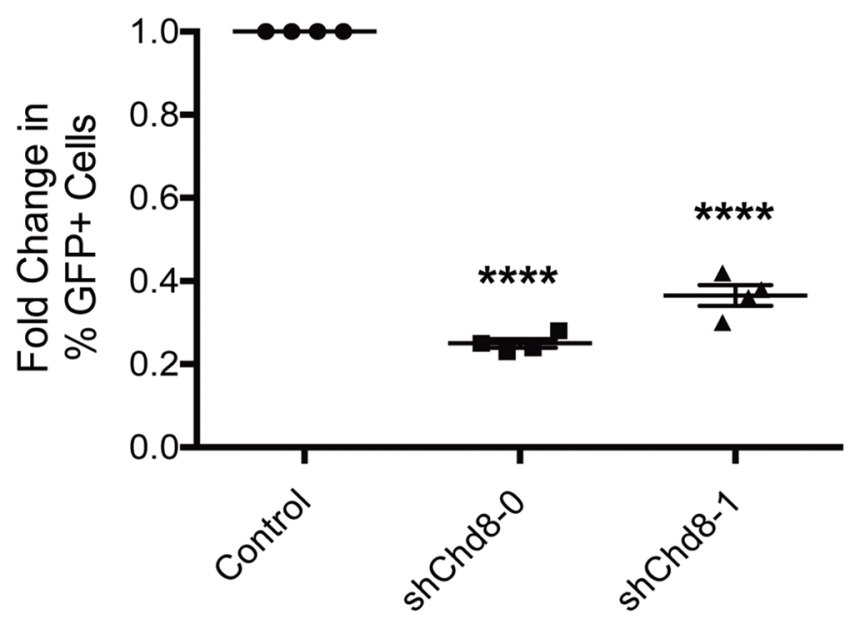

F

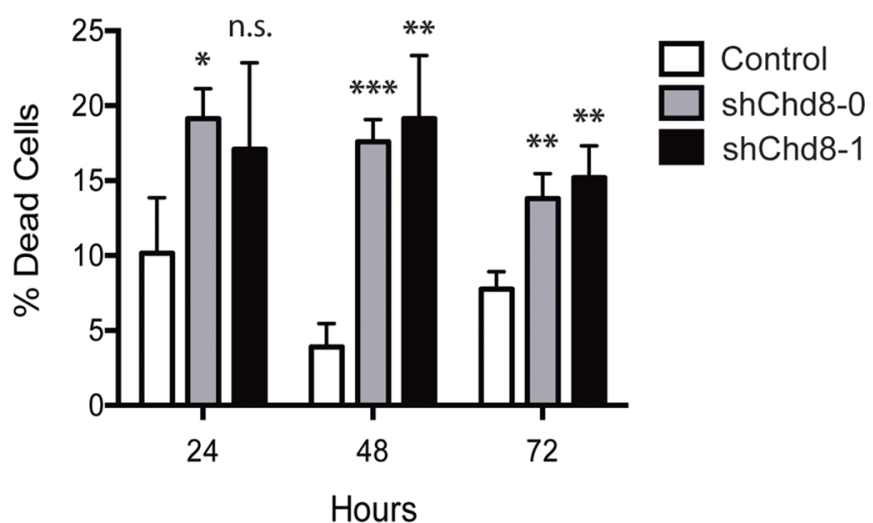

Fig 5. CHD8 depletion is detrimental in multiple B cell malignancies and normal pre-B cells. (A) Western blot showing CHD8 expression in B-ALL cells and untransformed pre-B cells. (B) Graph showing results of growth competition assay with pre-B cells transduced with the indicated constructs. Shown are averages \pm SD. Fold changes were calculated from day 2 to day 10 after retroviral infection and normalized to an empty vector control. (C) Western blot showing decreased CHD8 expression following transduction of $\mathrm{E} \mu-\mathrm{myc} A \mathrm{Ar}^{-/}$cells with the indicated shChd8 constructs. (D) Graph showing results of in vitro growth competition assays with $\mathrm{E} \mu$-myc cells transduced with the indicated constructs. Shown are averages \pm SEM of four independent experiments. Fold changes were calculated from day 2 to day 10 after retroviral infection and normalized to an empty vector control. (E) Growth curves of E $\mu$-myc cells transduced with the indicated constructs. Shown are averages \pm SD. (F) Bar graph showing percentages of dead cells following Chd8 knockdown in E $\mu$-myc cells. Shown are averages $\pm \mathrm{SD} .{ }^{*} \mathrm{P}<0.05,{ }^{*} \mathrm{P}<0.01,{ }^{* *} \mathrm{P}<0.001,{ }^{* * * *} \mathrm{P}<0.0001$

doi:10.1371/journal.pone.0143275.g005 
found that a T-ALL cell line that constitutively expresses the intracellular domain of Notch ("Top Notch") [33], and thus exhibits constitutive activation of the Notch pathway, is less dependent on CHD8 expression for survival than the B cell malignancies tested. Top Notch cells expressing shChd8-1 did not deplete in in vitro growth competition assays (Fig 6A). While shChd8-0 caused depletion that was determined to be statistically significant, this depletion was less than that seen in B-ALL cells.

We also examined CHD8 dependency in a spontaneous T-cell lymphoma cell line derived from a $\mathrm{K}-\mathrm{ras}{ }^{L A 2 /+} ; p 53^{L S L / L S L}$ mouse (hereafter referred to as KP). These cells express oncogenic K-ras ${ }^{\text {G12D }}$ and are functionally p53-null [34,35]. KP lymphoma cells deplete upon CHD8 knockdown in growth competition assays, but to a lesser extent than B cell malignancies (Fig 6B). The distinction between CHD8 dependencies in these two $\mathrm{T}$ cell populations could shed light on the mechanism of CHD8 activity. To determine if constitutive Notch signaling could rescue the CHD8 knockdown phenotype, KP lymphoma cells were transduced with the Notch intracellular domain (ICN) linked to a GFP marker, or a GFP marker alone (S7 Fig) [36]. Ectopic ICN expression is lethal to B cells [37], so they could not be used for these experiments. Transduced KP cells were sorted to obtain pure GFP+ populations, then partially transduced with one of two shChd8 constructs linked to a tdTomato marker, or a vector control. Cells were analyzed by flow cytometry to assess the change in percentage of tdTomato+ cells in each population. While cells expressing shChd8 on the GFP+ control background depleted to a significant extent, cells expressing shChd8 on the ICN-transduced background were partially rescued from depletion (Fig 6C). This result indicates that constitutive Notch signaling can attenuate the detrimental effects of CHD8 knockdown in KP lymphoma cells, possibly overriding a reduction in survival or growth signals caused by CHD8 depletion that other oncogenic signaling pathways are unable to compensate for.

\section{Discussion}

We have demonstrated that CHD8 is necessary for survival of B lymphoid malignancies. This dependency exists in both the in vitro and in vivo settings, indicating that CHD8 functions in a cell-autonomous manner and its depletion does not alter interactions of B-ALL cells with their microenvironment. When we examined the effects of CHD8 depletion on leukemic cell proliferation, we uncovered a cell death phenotype not preceded by cell cycle arrest. Others have shown that CHD8 knockdown in cervical carcinoma cells leads to G1 arrest facilitated by downregulation of CCNE2 and TYMS, genes required for transition into $S$ phase [21]. However, when we examined cell cycle profiles of B-ALL cells upon CHD8 knockdown, we observed no difference between control and CHD8-depleted cells. It is possible that the differences between our results and those of Rodriguez-Paredes et al. are due to the distinct signaling contexts in the two cell types used.

Several early studies observed expression of a truncated N-terminal CHD8 isoform termed Duplin $[18,19]$. We found that exogenous expression of Duplin did not compensate for CHD8 knockdown, suggesting that domains unique to full-length CHD8 are crucial for its function in B-ALL cells. The second chromodomain, absent in Duplin, has been shown to enable binding to histone $\mathrm{H} 3$ [21], and the BRK domains at the C-terminus have been demonstrated to interact with the chromatin insulator CTCF [29]. It is curious that, unlike results of previous studies, endogenous Duplin expression was not found in B-ALL cells or in normal mouse tissues by qPCR. Bioinformatics databases currently show truncated isoforms of CHD8 only in rat, so it is likely that murine Duplin is an experimental artifact not physiologically expressed.

Previous work by our group has highlighted genes whose effect on survival is context-specific between B and T cell malignancies [5]. For example, the chromatin regulator PHF6 is 
A

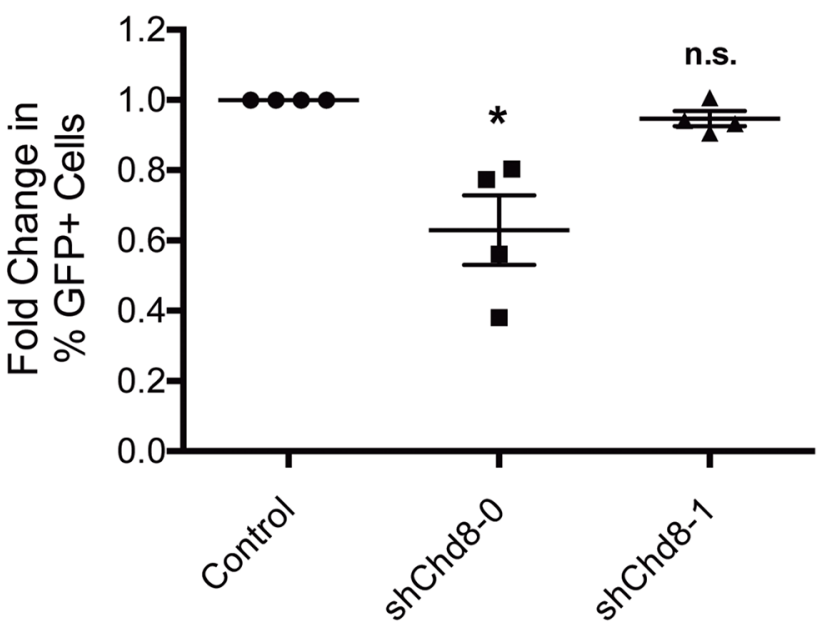

B

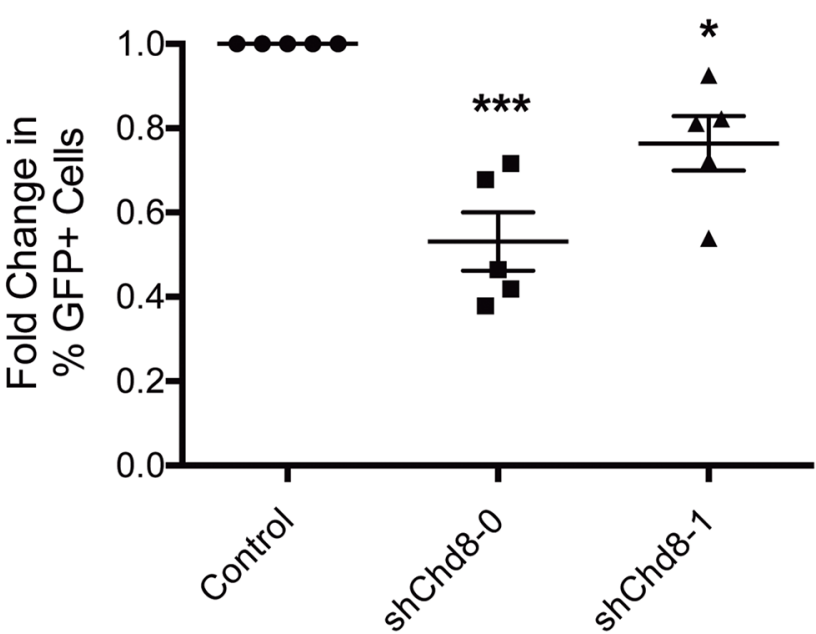

C

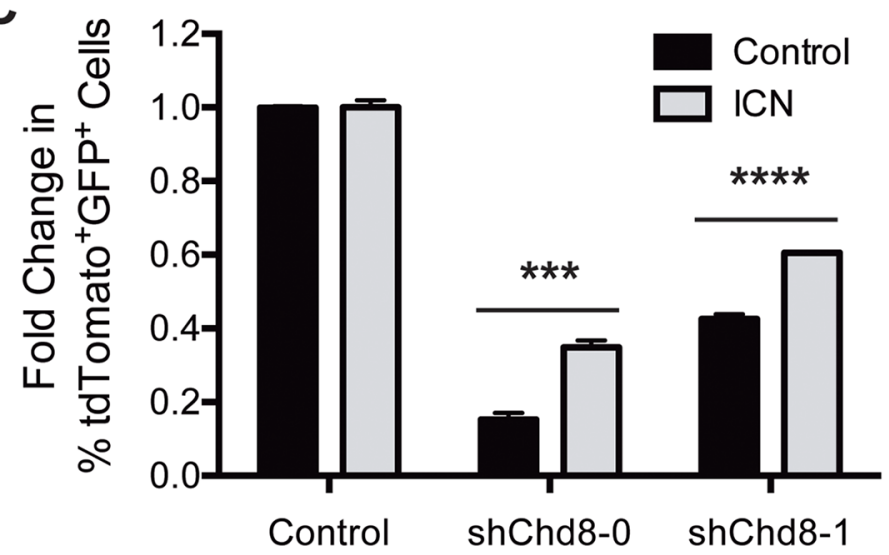

CHD8

HSP90

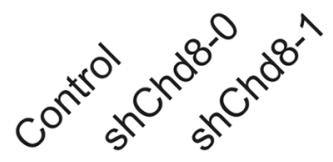
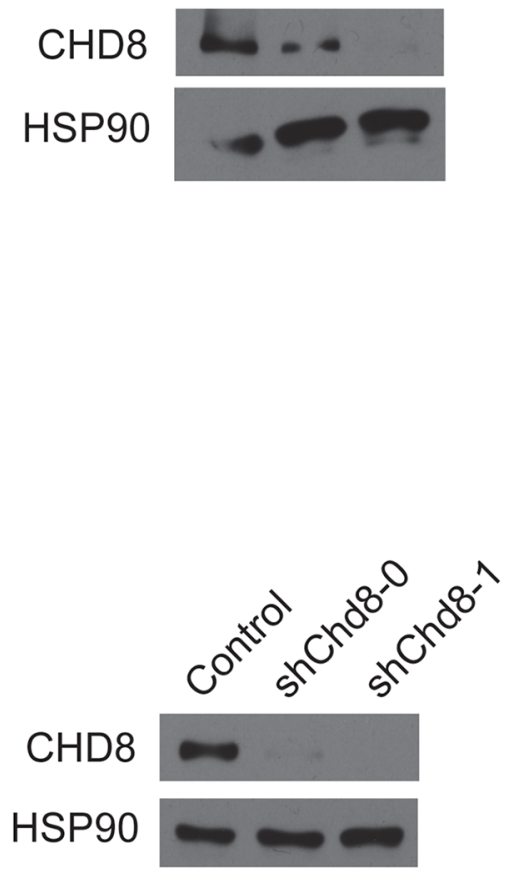

Fig 6. T cell malignancies exhibit different requirements for CHD8 expression that can be partially alleviated by constitutive Notch signaling. (A) (Left) Graph showing results of in vitro growth competition assays with Top Notch cells. Shown are averages \pm SEM of four independent experiments. (Right) Western blot showing decreased CHD8 expression in Top Notch cells following transduction with shChd8-0 or -1. (B) (Left) Graph showing results of in vitro growth competition assays with KP lymphoma cells. Shown are averages \pm SEM of five independent experiments. (Right) Western blot showing decreased CHD8 expression in KP lymphoma cells following transduction with shChd8-0 or -1. Fold changes of competition assays were calculated from day 2 to day 10 after retroviral infection and normalized to an empty vector control. (C) Graph showing results of ICN rescue experiment with KP lymphoma cells. Shown 
required for survival of B-ALL cells, but loss-of-function is selected for in T-ALL [38]. Factors such as HES1 that promote T lineage development are often lethal when ectopically expressed in the B cell lineage [37]. We found that Top Notch T-ALL cells are significantly less dependent on CHD8 expression than the B cell malignancies tested. The results of the ICN rescue experiment indicate that constitutive Notch signaling can partially compensate for CHD8 knockdown in a $\mathrm{T}$ cell malignancy, consistent with results of a recent screen for chromatin regulators that are essential in GSI-resistant cells [8]. CHD8 was among the proteins found to be necessary for survival of resistant cells but not syngeneic GSI-sensitive cells that continued to exhibit high levels of ICN and a more open chromatin conformation. These results suggest that CHD8 and high Notch signaling are able to compensate for each other's absence through mechanisms that are currently unclear. It is possible that CHD8 compensates for chromatin compaction upon Notch inhibition by promoting transcription. Alternatively, CHD8-mediated chromatin compaction could promote survival of GSI-resistant cells that have downregulated Notch signaling. Additional investigation is needed to determine the lineage-specific mechanism of CHD8's pro-survival activity.

A growing body of literature shows that inhibition of chromatin-modifying proteins is a promising field of investigation and drug development. Inhibiting these factors may correct global transcriptional deregulation instigated by events such as Myc overexpression. Our work suggests CHD8 is a potential drug target in B cell malignancies provided toxicity in normal hematopoietic cells is not limiting. Our results and those of others indicate that inhibiting CHD8 would not be as effective in T cell malignancies driven by Notch signaling, and could be counter-productive in certain solid tumors. However, CHD8 inhibition could synergize with $\gamma$ secretase inhibitors in cells that have become resistant through epigenetic mechanisms. When compared to our knowledge of other chromatin-modifying proteins, our understanding of the function of CHD8 is relatively incomplete. Nonetheless, it is clear that CHD8 has critical roles in cell survival, and additional investigation should be conducted to better define its place within central signaling pathways.

\section{Supporting Information}

S1 Fig. CHD8 shRNAs cause similar levels of depletion of transduced cells in in vitro competition assays. Graph showing depletion of shRNA-expressing B-ALL cells in vitro over time. Shown are averages \pm SEM of three independent experiments.

(PDF)

S2 Fig. Deletions in Chd8 sequence following transduction with sgRNAs targeting Chd8. A region surrounding the sgRNA binding site was PCR-amplified from genomic DNA extracted from the indicated clonal populations. PAM sequences are indicated in italics and stop codons are indicated in bold. Chd8 WT indicates the normal gene sequence. (PDF)

S3 Fig. CHD8 expression is retained in cells transduced with sgRNAs targeted to Renilla luciferase. Western blot showing CHD8 expression in B-ALL cells transduced with sgRNAs targeted to Renilla luciferase. Image was altered to juxtapose discontinuous lanes run on the same gel.

$(\mathrm{PDF})$ 
S4 Fig. Locations in Chd8 targeted by shRNAs.

(PDF)

S5 Fig. shChd8-mediated cell death is not rescued by treatment with the pan-caspase inhibitor ZVAD-fmk. BCR-Abl+ B-ALL cells transduced with TRMPVIR-shRen or TRMPVIRshChd8-1 were plated in triplicate with doxycycline and ZVAD-fmk or DMSO vehicle control. The percentage of Venus ${ }^{+} \mathrm{dsRed}^{+}$cells was assessed every two days by flow cytometry, and the fold change from time of plating to the end of the assay (eight days) was calculated. Shown are averages and SD of triplicate wells.

(PDF)

S6 Fig. Caspase 3 cleavage is not observed upon induction of shChd8-1. A pure population of BCR-Abl+ B-ALL cells expressing TRMPVIR shChd8-1 was plated with or without doxycycline and collected at the indicated times. Protein lysates were generated and analyzed by western blot for the presence of cleaved $(17 \mathrm{kDa})$ and pro-caspase $3(53 \mathrm{kDa})$. Actin was used as a loading control. Image cropped to align discontinuous lanes from the same membrane. (PDF)

S7 Fig. ICN is overexpressed in KP lymphoma cells transduced with MIG-ICN. Western blot showing expression of ICN in KP lymphoma cells following transduction with MIG-ICN. (PDF)

S1 Table. Sequences of shRNAs targeting Chd8. (XLSX)

S2 Table. Sequences of PCR and sequencing primers used in the study. (XLSX)

S3 Table. Sequences used to construct sgRNAs used in the study. (XLSX)

S4 Table. List of antibodies used in the study.

(XLSX)

S5 Table. Sequences of qPCR primers used in the study.

(XLSX)

S6 Table. Statistical analysis of Chd8-knockout survival study (Fig 2C).

(XLSX)

\section{Acknowledgments}

The authors thank Charles Sherr for BCR-Abl+ B-ALL cells, Anthony Capobianco for Top Notch T-ALL cells, Tyler Jacks for K-ras ${ }^{L A 2 /+} ; p 53^{L S L / L S L} \mathrm{~T}$-cell lymphoma cells, and Warren Pear for pMIG-ICN.

\section{Author Contributions}

Conceived and designed the experiments: MTH JRS. Performed the experiments: JRS. Analyzed the data: MTH JRS. Contributed reagents/materials/analysis tools: MTH JRS. Wrote the paper: MTH JRS. 


\section{References}

1. Kurzrock R, Kantarjian HM, Druker BJ, Talpaz M. Philadelphia chromosome-positive leukemias: from basic mechanisms to molecular therapeutics. Ann Intern Med. 2003 May 20; 138(10):819-30. PMID: 12755554

2. Hu Y, Swerdlow S, Duffy TM, Weinmann R, Lee FY, Li S. Targeting multiple kinase pathways in leukemic progenitors and stem cells is essential for improved treatment of $\mathrm{Ph}+$ leukemia in mice. Proc Natl Acad Sci U S A. 2006; 103:16870-5. PMID: 17077147

3. Liu-Dumlao T, Kantarjian H, Thomas DA, O'Brien S, Ravandi F. Philadelphia-positive acute lymphoblastic leukemia: Current treatment options. Curr Oncol Rep. 2012; 14:387-94. doi: 10.1007/s11912012-0247-7 PMID: 22669492

4. Talpaz M, Shah NP, Kantarjian H, Donato N, Nicoll J, Paquette R, et al. Dasatinib in imatinib-resistant Philadelphia chromosome-positive leukemias. N Engl J Med. 2006 Jun 15; 354(24):2531-41. PMID: 16775234

5. Meacham CE, Lawton LN, Soto-Feliciano YM, Pritchard JR, Joughin BA, Ehrenberger T, et al. A genome-scale in vivo loss-of-function screen identifies $\mathrm{Phf} 6$ as a lineage-specific regulator of leukemia cell growth. Genes Dev. 2008;483-8.

6. Williams RT, den Besten W, Sherr CJ. Cytokine-dependent imatinib resistance in mouse BCR-ABL+, Arf-null lymphoblastic leukemia. Genes Dev. 2007 Sep 15; 21(18):2283-7. PMID: 17761812

7. Mullighan CG, Williams RT, Downing JR, Sherr CJ. Failure of CDKN2A/B (INK4A/B-ARF)-mediated tumor suppression and resistance to targeted therapy in acute lymphoblastic leukemia induced by BCR-ABL. Genes Dev. 2008 Jun 1; 22(11):1411-5. doi: 10.1101/gad.1673908 PMID: 18519632

8. Knoechel B, Roderick JE, Williamson KE, Zhu J, Lohr JG, Cotton MJ, et al. An epigenetic mechanism of resistance to targeted therapy in T cell acute lymphoblastic leukemia. Nat Genet. 2014 Apr; 46 (4):364-70. doi: 10.1038/ng.2913 PMID: 24584072

9. Asangani I a, Dommeti VL, Wang X, Malik R, Cieslik M, Yang R, et al. Therapeutic targeting of BET bromodomain proteins in castration-resistant prostate cancer. Nature. 2014; 510:278-82. doi: 10.1038/ nature13229 PMID: 24759320

10. Nie J, Liu L, Li X, Han W. Decitabine, a new star in epigenetic therapy: the clinical application and biological mechanism in solid tumors. Cancer Lett. 2014 Nov 1; 354(1):12-20. doi: 10.1016/j.canlet.2014. 08.010 PMID: 25130173

11. Talkowski ME, Rosenfeld JA, Blumenthal I, Pillalamarri V, Chiang C, Heilbut A, et al. Sequencing chromosomal abnormalities reveals neurodevelopmental loci that confer risk across diagnostic boundaries. Cell. 2012 Apr 27; 149(3):525-37. doi: 10.1016/j.cell.2012.03.028 PMID: 22521361

12. Neale BM, Kou Y, Liu L, Ma'ayan A, Samocha KE, Sabo A, et al. Patterns and rates of exonic de novo mutations in autism spectrum disorders. Nature. 2012 May 10; 485(7397):242-5. doi: 10.1038/ nature11011 PMID: 22495311

13. O'Roak BJ, Vives L, Fu W, Egertson JD, Stanaway IB, Phelps IG, et al. Multiplex targeted sequencing identifies recurrently mutated genes in autism spectrum disorders. Science. 2012 Dec 21; 338 (6114):1619-22. doi: 10.1126/science.1227764 PMID: 23160955

14. O'Roak BJ, Vives L, Girirajan S, Karakoc E, Krumm N, Coe BP, et al. Sporadic autism exomes reveal a highly interconnected protein network of de novo mutations. Nature. 2012. Apr 4; 485(7397):246-50. doi: 10.1038/nature10989 PMID: 22495309

15. Kim MS, Chung NG, Kang MR, Yoo NJ, Lee SH. Genetic and expressional alterations of CHD genes in gastric and colorectal cancers. Histopathology. 2011; 58:660-8. doi: 10.1111/j.1365-2559.2011.03819. x PMID: 21447119

16. Tahara T, Yamamoto E, Madireddi P, Suzuki H, Maruyama R, Chung W, et al. Colorectal carcinomas with CpG island methylator phenotype 1 frequently contain mutations in chromatin regulators. Gastroenterology. 2014 Mar; 146(2):530-8. doi: 10.1053/j.gastro.2013.10.060 PMID: 24211491

17. Bernier R, Golzio C, Xiong B, Stessman HA, Coe BP, Penn O, et al. Disruptive CHD8 Mutations Define a Subtype of Autism Early in Development. Cell. 2014. Jul 17; 158(2):263-76. doi: 10.1016/j.cell.2014. 06.017 PMID: 24998929

18. Sakamoto I, Kishida S, Fukui A, Kishida M, Yamamoto H, Hino S, et al. A novel beta-catenin-binding protein inhibits beta-catenin-dependent Tcf activation and axis formation. J Biol Chem. 2000 Oct 20; 275(42):32871-8. PMID: 10921920

19. Nishiyama M, Oshikawa $K$, Tsukada $Y$, Nakagawa T, lemura $S$, Natsume T, et al. CHD8 suppresses p53-mediated apoptosis through histone $\mathrm{H} 1$ recruitment during early embryogenesis. Nat Cell Biol. 2009; 11:172-82. doi: 10.1038/ncb1831 PMID: 19151705 
20. Nishiyama M, Skoultchi A, Nakayama K. Histone H1 Recruitment by CHD8 Is Essential for Suppression of the Wnt- $\beta$-Catenin Signaling Pathway. Mol Cell Biol. 2012. Jan 15; 32(2):501-12. doi: 10.1128/ MCB.06409-11 PMID: 22083958

21. Rodríguez-Paredes $M$, Ceballos-Chávez M, Esteller M, García-Domínguez M, Reyes JC. The chromatin remodeling factor $\mathrm{CHD} 8$ interacts with elongating RNA polymerase II and controls expression of the cyclin E2 gene. Nucleic Acids Res. 2009; 37:2449-60. doi: 10.1093/nar/gkp101 PMID: 19255092

22. Subtil-Rodríguez $\mathrm{A}$, Vázquez-Chávez $\mathrm{E}$, Ceballos-Chávez M, Rodríguez-Paredes M, Martín-Subero J, Esteller M, et al. The chromatin remodeller CHD8 is required for E2F-dependent transcription activation of S-phase genes. Nucleic Acids Res. 2013;1-12.

23. Menon T, Yates JA, Bochar DA. Regulation of androgen-responsive transcription by the chromatin remodeling factor CHD8. Mol Endocrinol. 2010; 24:1165-74. doi: 10.1210/me.2009-0421 PMID: 20308527

24. Sawada G, Ueo H, Matsumura T, Uchi R, Ishibashi M, Mima K, et al. CHD8 is an independent prognostic indicator that regulates Wnt/ $\beta$-catenin signaling and the cell cycle in gastric cancer. Oncol Rep. 2013. Sep; 30(3):1137-42. doi: 10.3892/or.2013.2597 PMID: 23835524

25. Dickins RA, Hemann MT, Zilfou JT, Simpson DR, Ibarra I, Hannon GJ, et al. Probing tumor phenotypes using stable and regulated synthetic microRNA precursors. Nat Genet. 2005; 37:1289-95. PMID: 16200064

26. Zuber J, McJunkin K, Fellmann C, Dow LE, Taylor MJ, Hannon GJ, et al. Toolkit for evaluating genes required for proliferation and survival using tetracycline-regulated RNAi. Nat Biotechnol. 2011 Jan 1; 29 (1):79-83. doi: 10.1038/nbt.1720 PMID: 21131983

27. Swift S, Lorens J, Achacoso P, Nolan GP. Rapid production of retroviruses for efficient gene delivery to mammalian cells using 293T cell-based systems. Curr Protoc Immunol. 2001;Chapter 10:Unit 10.17C.

28. Ran FA, Hsu PD, Wright J, Agarwala V, Scott D a, Zhang F. Genome engineering using the CRISPRCas9 system. Nat Protoc. 2013; 8:2281-308. doi: 10.1038/nprot.2013.143 PMID: 24157548

29. Ishihara K, Oshimura M, Nakao M. CTCF-dependent chromatin insulator is linked to epigenetic remodeling. Mol Cell. 2006 Sep 1; 23(5):733-42. PMID: 16949368

30. Dalla-Favera R, Bregni M, Erikson J, Patterson D, Gallo RC, Croce CM. Human c-myc onc gene is located on the region of chromosome 8 that is translocated in Burkitt lymphoma cells. Proc Natl Acad Sci U S A. 1982 Dec 1; 79(24):7824-7. PMID: 6961453

31. Taub R, Kirsch I, Morton C, Lenoir G, Swan D, Tronick S, et al. Translocation of the c-myc gene into the immunoglobulin heavy chain locus in human Burkitt lymphoma and murine plasmacytoma cells. Proc Natl Acad Sci U S A. 1982; 79:7837-41. PMID: 6818551

32. Adams JM, Harris AW, Pinkert CA, Corcoran LM, Alexander WS, Cory S, et al. The c-myc oncogene driven by immunoglobulin enhancers induces lymphoid malignancy in transgenic mice. Nature. 1985 Jan 1; 318(6046):533-8. PMID: 3906410

33. Beverly LJ, Felsher DW, Capobianco AJ. Suppression of $\mathrm{p} 53$ by Notch in lymphomagenesis: implications for initiation and regression. Cancer Res. 2005 Aug 15; 65(16):7159-68. PMID: 16103066

34. Johnson L, Mercer K, Greenbaum D, Bronson RT, Crowley D, Tuveson DA, et al. Somatic activation of the K-ras oncogene causes early onset lung cancer in mice. Nature. 2001; 410:1111-6. PMID: 11323676

35. Ventura A, Kirsch DG, McLaughlin ME, Tuveson DA, Grimm J, Lintault L, et al. Restoration of p53 function leads to tumour regression in vivo. Nature. 2007; 445:661-5. PMID: 17251932

36. Aster JC, Xu L, Karnell FG, Patriub V, Pui JC, Pear WS. Essential roles for ankyrin repeat and transactivation domains in induction of T-cell leukemia by notch1. Mol Cell Biol. 2000; 20:7505-15. PMID: 11003647

37. Zweidler-McKay PA, He Y, Xu L, Rodriguez CG, Karnell FG, Carpenter AC, et al. Notch signaling is a potent inducer of growth arrest and apoptosis in a wide range of B-cell malignancies. Blood. $2005 \mathrm{Dec}$ 1; 106(12):3898-906. PMID: 16118316

38. Van Vlierberghe P, Palomero T, Khiabanian H, Van der Meulen J, Castillo M, Van Roy N, et al. PHF6 mutations in T-cell acute lymphoblastic leukemia. Nat Genet. 2010; 42:338-42. doi: 10.1038/ng.542 PMID: 20228800 